\title{
Will Rogers Paradox in Basketball Analytics
}

\author{
Ricardo Valerdi* \\ Department of Systems \& Industrial Engineering, University of Arizona, Tucson, Arizona, USA
}

*Corresponding author: Ricardo Valerdi, Department of Systems \& Industrial Engineering, University of Arizona, Tucson, Arizona, USA.

Received Date: May 19, 2021

Published Date: May 28, 2021

\begin{abstract}
Statistics is full of paradoxes, logically self-contradictory statements that run contrary to one's expectation. Here we explore Will Rogers Paradox which presents itself when changes in criteria for assigning data elements to a group can produce spurious results even though the values of the individual data elements have not changed. An example in basketball analytics is provided to illustrate the application of the paradox.
\end{abstract}

\section{Introduction}

The Will Rogers paradox comes from the American comedian Will Rogers, who joked that "when the Okies left Oklahoma and moved to California, they raised the average intelligence in both states." In other words, the Will Rogers Paradox occurs when moving an element from one set to another set raises the average values of both sets even if the value of an element remains unchanged.

\section{An Example of Will Rogers Paradox}

The Will Rogers paradox has been observed in professional sports such as baseball, hockey, football and professional basketball [1]. Here we illustrate the paradox by analyzing a college basketball player in the U.S. named Alex Barcello. Mr. Barcello began his collegiate basketball career at the University of Arizona. He had mixed success with that team during his first two years (known as freshman and sophomore seasons), after which he decided to transfer to Brigham Young University, citing the potential for more playing time and better team chemistry.

By doing so, Barcello actually improved both teams, at least statistically speaking. This may be counterintuitive because it would be expected that the movement of a player from one team to another would result in making one team better and the other worse. It turns out that Barcello's move resulted in a paradoxical result: he made both teams better.

By transferring from the University of Arizona to Brigham Young University, Barcello improved both teams' statistics including: Field Goal \%, 3-point \%, and Points Per Game. The reason for the improvement is because Barcello moved from being an underperformer at Arizona to be an overperformer at BYU. In his second season at the University of Arizona he was the tenth best player on the team, out of fourteen. At BYU, he was the fourth best player. This made both teams better because Barcello's departure raised the average (mean) in both places, resulting in a win-win situation.

By examining Field Goal \% during Arizona's final season with Barcello (2018-19) and their first season without him (2019-20), there is a noticeable improvement in Field Goal \% from $42.7 \%$ to $44.8 \%$, as shown in Table 1 .

Similarly, BYU's Field Goal \% jumped from $46.8 \%$ to $50.4 \%$ before (2018-19) and after Barcello joined the team (2019-20), as shown in Table 2. 
Table 1: Field Goal \% Comparison at the University of Arizona.

\begin{tabular}{|c|c|c|}
\hline & University of Arizona 2018-19 season with Barcello & University of Arizona 2019-20 season without Barcello \\
\hline Field Goal \% & $42.70 \%$ & $44.80 \%$ \\
\hline
\end{tabular}

Table 2: Field Goal \% Comparison at BYU.

\begin{tabular}{|c|c|c|}
\hline & BYU 2018-19 season without Barcello & BYU 2019-20 season with Barcello \\
\hline Field Goal \% & $46.80 \%$ & $50.40 \%$ \\
\hline & Barcello's sophomore season at Arizona (2018-19) & Barcello's junior season at BYU (2019-20) \\
\hline Field Goal \% & $39.30 \%$ & $49.30 \%$ \\
\hline
\end{tabular}

As shown in Table 3, Barcello's Field Goal \% was below the team average at Arizona during his sophomore season (Arizona 42.7\% > Barcello 39.3\%). At BYU he was very close to the team average during his third season, referred to as his junior season (BYU $50.4 \%$ $\approx$ Barcello 49.3\%).

A visual representation of the same data is shown in Figure 1 below. It illustrates the rising mean for both teams from one season to the next thanks to, among other things, Barcello's transfer.

The same win-win outcome exists for Arizona and BYU with other team statistics during the same two seasons: 3-point shooting percentage and points per game improve for both teams. But for this to really be considered a win-win, each team's winning percentage must increase. Which it did.

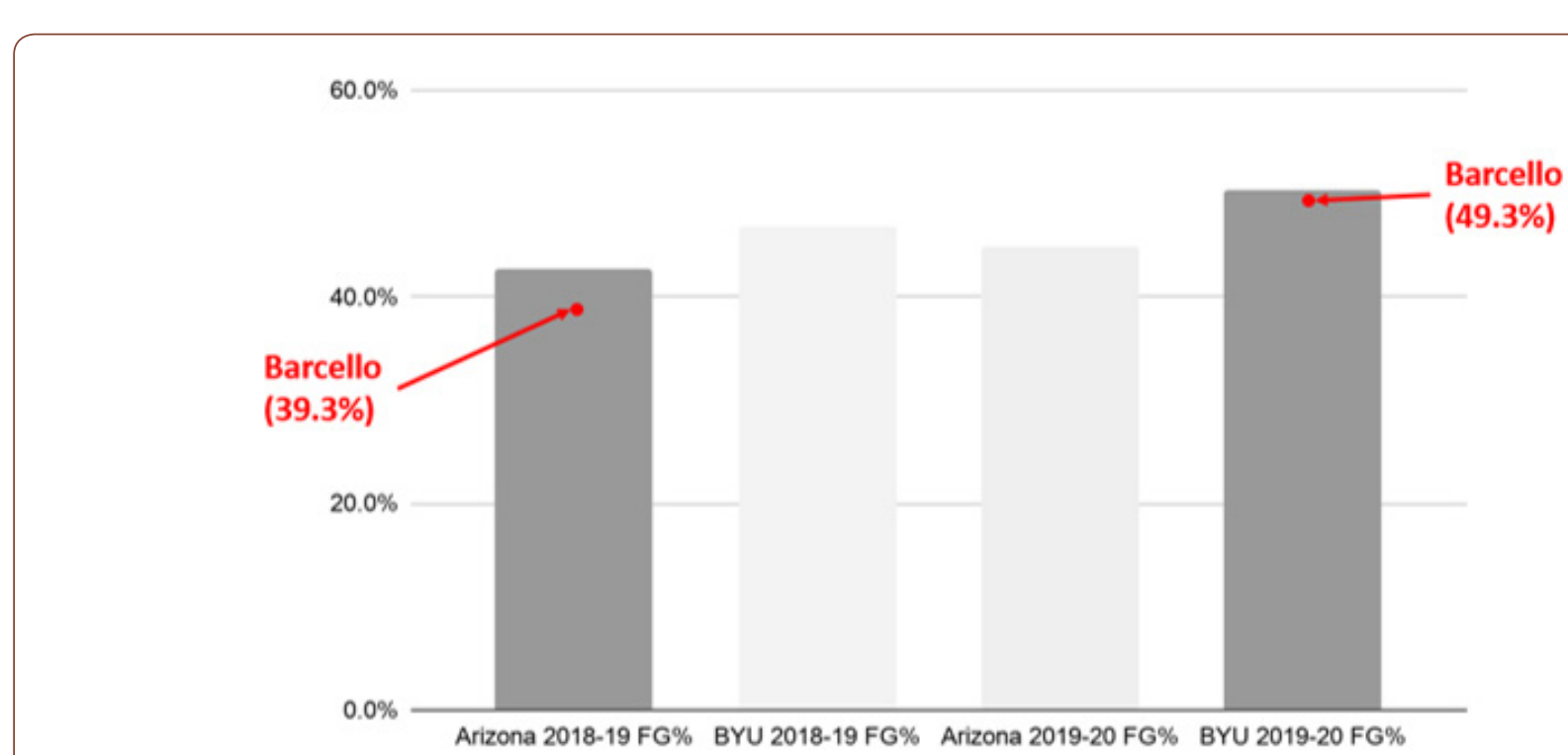

Figure 1: Alex Barcello Makes Both Teams Better by Transferring Schools.

Arizona's overall record improved from 17 wins and 15 losses (53.1 win \%) during Barcello's sophomore season to 21 wins and 11 losses (65.6 win \%) after his departure. BYU's overall record also improved. Before Barcello they notched 19 wins and 13 losses (59.4 win \%) but with Barcello on the floor they saw a dramatic jump to 24 wins and 8 losses (75 wins \%).

\section{Discussion}

There are a number of possible reasons for this result. Assuming Barcello didn't suddenly change his shooting style or training regimen from one season to the other, let's consider him the only constant. But the teams, playbooks, and coaches around him changed. This new environment could have created better team dynamics resulting in an improvement in his individual performance.

The competition around him also changed. One measure of this is a team's strength of schedule, which can be calculated from the win-loss record of their opponents. Arizona plays in the Pacific-12 conference against a more difficult schedule (ranking 39th in strength of schedule) while BYU plays in the West Coast Conference with a slightly less difficult strength of schedule (ranking 70th most difficult out of 353 college basketball programs). Presumably the easier competition allowed Barcello to dominate as a member of the BYU team which he was unable to do as a member of the University of Arizona team.

Whatever the reasons, the main message should not be lost. That is, when a datapoint is moved from one group to another - if 
the point is below the average of the group it is leaving, but above the average of the one it is joining- both groups' averages will increase. This can occur in many situations, such as medicine [2], where there are data points classified into two groups as well as movement of data between groups.

\section{Acknowledgement}

None.

\section{Conflict of Interest}

No conflict of interest.

\section{References}

1. Bill Simmons (2009) Ewing Theory 101, ESPN Page 2.

2. Maria Pia Sormani (2009) The Will Rogers phenomenon: the effect of different diagnostic criteria. Journal of the Neurological Sciences 287(1): S46-S49. 